\title{
Spontaneous fracture of an uncovered enteral stent with proximal migration of fractured segment into cervical esophagus: first report
}

A 50-year-old woman underwent endoscopic placement of a biliary self-expandable metallic stent (SEMS) and a $22 \times 90 \mathrm{~mm}$ WallFlex ${ }^{\mathrm{TM}}$ duodenal stent (Boston Scientific, Natick, Massachusetts, USA) across an inoperable periampullary adenocarcinoma. Eighteen months later, the patient presented with nonbilious vomiting. A clinical diagnosis of gastric outlet obstruction due to disease progression was made. Endoscopy revealed a normal esophagus, dilated stomach, and narrowing between the first and second parts of the duodenum, but the stent was not clearly visualized.

One week later, the patient underwent a water-soluble contrast study for assessment of the gastric outlet obstruction. Preliminary fluoroscopy revealed a radiopaque foreign body in the cervical esophagus, which was presumed to be the displaced fragment of the stent ( $\bullet$ Fig. 1 a). There was free flow of contrast across the fragment ( $\bullet$ Fig. 1 b). Luminal obstruction was apparent at the proximal end of the fractured stent in the second part of the duodenum with abrupt cutoff and prestenotic dilatation of the proximal duodenum and stomach ( $\bullet$ Fig. 2).

At endoscopy, the stent fragment, with a partially disrupted mesh, was seen just below the cricopharynx ( $\mathrm{Fig} .3 \mathrm{a}$ ).

It was retrieved by grasping it by its sides with two forceps, using a double-channel endoscope (Fujinon, Tokyo, Japan) (ه Fig. 3b).

Migration is a known complication of enteral SEMS with reported rates of up to $5 \%$ [1]. Distal migration is the norm and proximal migration is an exceptional event. The incidence of SEMS fracture and the exact reasons for this complication are elusive. Acid corrosion, thermal overstrain induced by laser application, and defective material at the time of deployment are some of the proposed explanations $[2,3]$. However, there was no obvious reason for the cervical esophageal migration of the fractured segment in our patient, and we hypothesize that the reverse peristalsis accompanying the frequent episodes of vomiting was responsible for this unusual presentation.
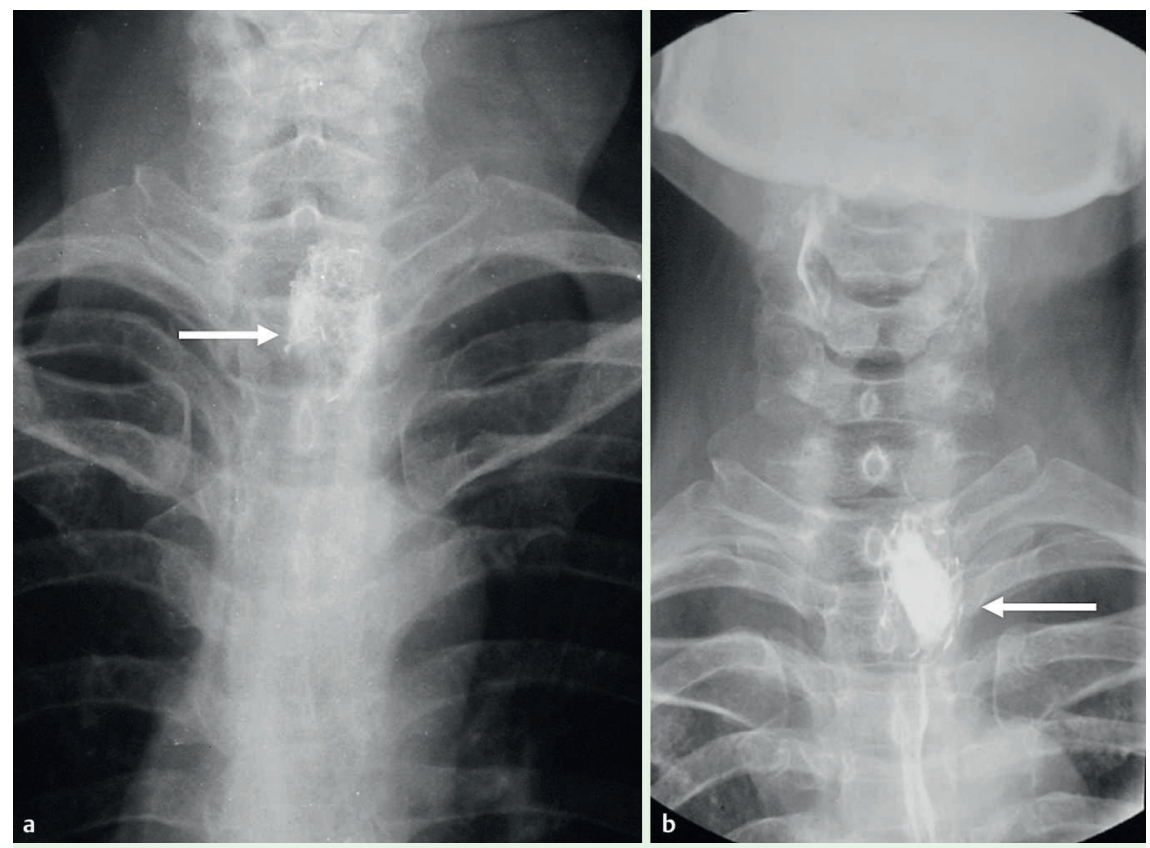

Fig. 1 a Preliminary fluoroscopy revealed a fractured stent fragment with partially disrupted mesh in the cervical esophagus (arrow). $\mathbf{b}$ Contrast was entrapped in the interstices of the mesh in the empty phase (arrow). There was no mediastinal leak.

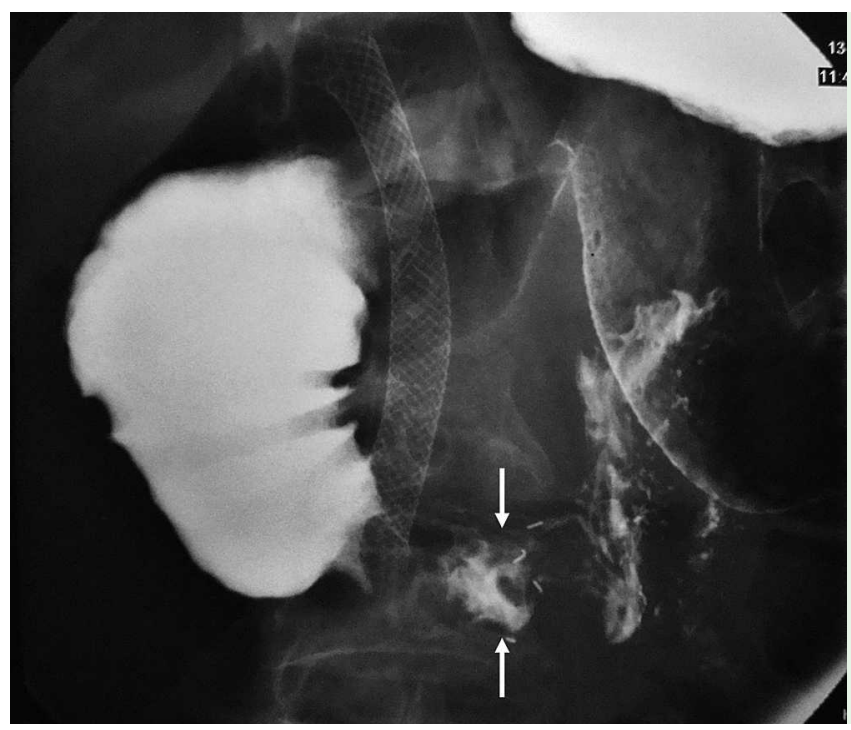

Fig. 2 The fractured enteral stent (arrows) with duodenal obstruction and prestenotic dilatation.

Endoscopic removal of stents that have migrated into the esophagus should be considered after ruling out potential complications with a water-soluble contrast study.

Endoscopy_UCTN_Code_CPL_1AH_2AD
A. H. Goenka ${ }^{1}$, P. K. Garg ${ }^{2}$, R. Sharma ${ }^{1}$, B. Sharma ${ }^{2}$

Department of Radiodiagnosis, All India Institute of Medical Sciences, New Delhi, India

2 Department of Gastroenterology, All India Institute of Medical Sciences, New Delhi, India 

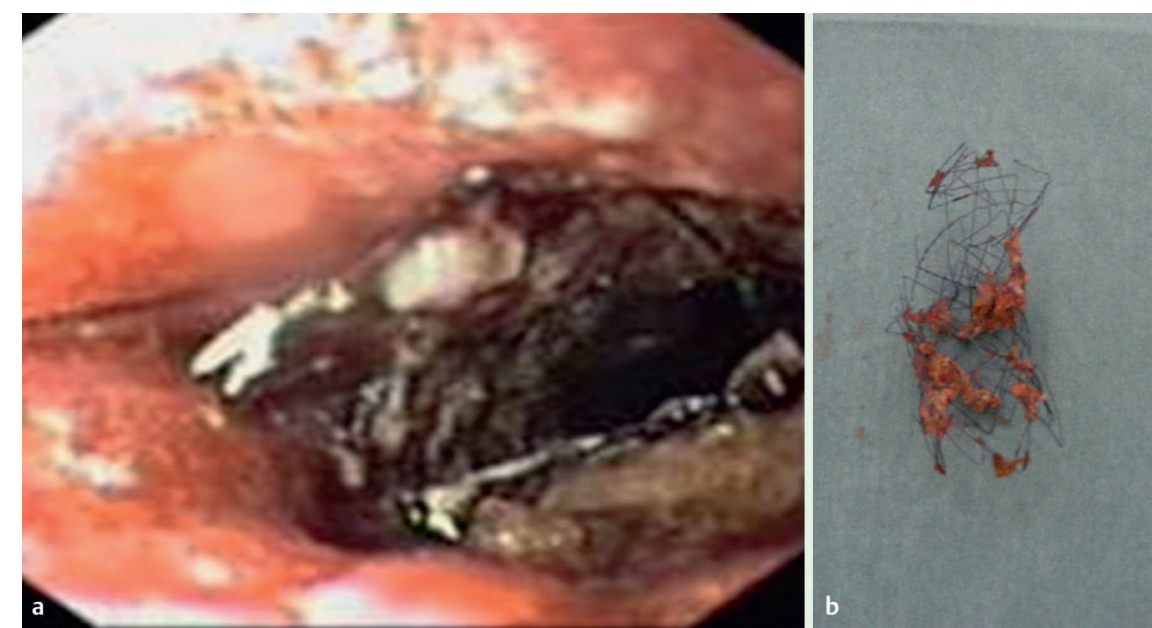

Fig. 3 a On endoscopy, the fractured fragment was visualized just below the cricopharynx. There was no evidence of deep esophageal injury. $\mathbf{b}$ Post-retrieval specimen.

\section{References}

1 Dormann A, Meisner S, Verin $N$ et al. Self-expanding metal stents for gastroduodenal malignancies: systematic review of their clinical effectiveness. Endoscopy 2004; 36: $543-550$

2 Schoefl $R$, Winkelbauer $F$, Haefner $M$ et al. Two cases of fractured esophageal nitinol stents. Endoscopy 1996; 28: 518-520

3 Grimley CE, Bowling TE. Oesophageal metallic stent dysfunction: first reported case of stent fracture and separation. Endoscopy 1999; $31: 45$

\section{Bibliography}

DOI $10.1055 / \mathrm{s}-0029-1214864$

Endoscopy 2009; 41: E204-E205

(c) Georg Thieme Verlag KG Stuttgart · New York . ISSN 0013-726X

\section{Corresponding author}

\section{R. Sharma}

Department of Radiodiagnosis

All India Institute of Medical Sciences (AlIMS)

Ansari Nagar

New Delhi - 110029

India

Fax: +91-11-26588663

raju152@yahoo.com 